\title{
Estrongiloidíase disseminada em paciente de transplante renal e pancreático: revisão de literatura baseado em caso clínico
}

Disseminated strongyloidiasis in kidney pancreatic transplant patient: a literature review based on a clinical case

Estrongiloidiaseis diseminada en paciente de trasplante de riñon pancreático: revisión de la literatura baseada en un caso clínico

José Hícaro Hellano Gonçalves Lima Paiva ORCID: https://orcid.org/0000-0002-6232-003X Hospital Geral Dr Cesar Carls, Brasil E-mail: hellanohicaro@gmail.com.

Marina Seixas Studart e Neves Longuinho ORCID: https://orcid.org/0000-0002-3070-8486 Hospital Geral de Fortaleza, Brasil E-mail: studartmarina@hotmail.com

Themístocles Mesquitas Teles de Carvalho ORCID: https://orcid.org/0000-0002-1388-5763 Hospital Geral de Fortaleza, Brasil E-mail: tmesquita_ce@hotmail.com

Germano de Garcia Alves Feitosa ORCID: https://orcid.org/0000-0003-0390-3267 Hospital Geral de Fortaleza, Brasil

E--mail: germano_feitosa@hotmail.com

Carla Barbosa Pontes ORCID: https://orcid.org/0000-0002-3318-1421 Hospital Geral de Fortaleza, Brasil E-mail: carlabpontes@hotmail.com

Camila Bezerra Bastos Limeira ORCID: https://orcid.org/0000-0003-1394-3377 Hospital Geral de Fortaleza, Brasil E-mail: camillabezerra@hotmail.com

Camila Monteiro Veras

ORCID: https://orcid.org/0000-0002-7536-8219 Hospital Geral de Fortaleza, Brasil E-mail: verascamila@gmail.com

Claudia Maria Costa de Oliveira ORCID: https://orcid.org/0000-0002-2795-6681 Hospital Geral de Fortaleza, Brasil E-mail: claudiadrl@gmail.com

Ítalo Rossy Sousa Pimentel ORCID: https://orcid.org/0000-0003-1372-1053 Hospital Geral de Fortaleza, Brasil E-mail: italorossy23@hotmail.com

Inácio Régis Nascimento de Oliveira ORCID: https://orcid.org/0000-0003-3728-4345

Hospital Geral de Fortaleza, Brasil

E-mail: inacioregis2005@yahoo.com.br

Luciana Maria Pereira de Oliveira ORCID: https://orcid.org/0000-0003-2147-6246

Hospital Geral de Fortaleza, Brasil E-mail: Luolivei72@gmail.com

Natália Stefani de Assunção Ferreira ORCID: https://orcid.org/0000-0002-5038-0879

Universidade Estadual do Ceará, Brasil E-mail: nataliastefani1@hotmail.com Ivelise Regina Canito Brasil ORCID: https://orcid.org/0000-0002-4886-7442 Hospital Geral de Fortaleza, Brasil E-mail: ivelise.canito@uece.br 


\title{
Resumo
}

O Strongyloides stercoralis é um helminto com distribuição mundial. As manifestações clínicas da estrongiloidíase disseminada variam amplamente e os pacientes imunocomprometidos apresentam risco de infecção sintomática. Um paciente do sexo masculino de 38 anos foi submetido a transplante duplo de pâncreas-rim em dezembro de 2019 devido a diabetes mellitus tipo 1 e insuficiência renal crônica dialítica. $O$ transplante ocorreu sem maiores intercorrências e o mesmo recebeu alta 10 dias após a realização do procedimento. Sessenta dias após o transplante foi internado na enfermaria de transplante renal apresentando náuseas, vômitos e dores abdominais iniciadas 5 dias antes. Com a possibilidade diagnóstica de gastroenterite infecciosa, foi iniciada antibioticoterapia. O paciente evoluiu com piora ventilatória associada a declínio do sensório, sendo encaminhado para Unidade de Terapia Intensiva, onde foi intubado e colocado em suporte ventilatório. Devido a piora clínica e hemodinâmica, necessitou iniciar de drogas vasoativas e aumentar o espectro da antibioticoterapia. Observou-se lesão serpiginosa púrpura em abdome, surgindo então a possibilidade de estrongiloidíase disseminada, posteriormente confirmada por lavado gástrico e cultura de aspirado traqueal positivas. Devido a impossibilidade do uso da via oral decorrente da instabilidade hemodinâmica e do volumoso resíduo gástrico, foi administrado ivermectina subcutânea. Quatro dias após o tratamento com ivermectina e antibioticoterapia guiada por cultura, o paciente faleceu. A estrongiloidíase disseminada é desafio para a saúde mundial, principalmente na população transplantada, pois a infecção está correlacionada a uma alta mortalidade.

Palavras-chave: Transplante de órgãos sólidos; Estrongiloidíase disseminada; Strongyloides Stercoralis; Imunocomprometido.

\begin{abstract}
Strongyloides stercoralis is a helminth with worldwide distribution and has the capacity to promote intestinal infection, which may progress to disseminated strongyloidiasis. The clinical manifestations of disseminated strongyloidiasis vary widely and immunocompromised patients are at risk of symptomatic infection. A 38-year-old man was submitted to double kidney-pancreas transplantation in December 2019 due to type 1 diabetes mellitus and chronic dialysis renal failure. He was admitted to the kidney transplant infirmary with nausea, vomiting and abdominal pain, which had started 5 days before. With the diagnostic possibility of infectious gastroenteritis, antibiotic therapy was started. The patient evolved with worsening ventilation associated with a decline in sensorium, being referred to the Intensive Care Unit, where he was intubated and placed on ventilatory support. As the patient was critically-ill and hemodynamically unstable, he required vasoactive drugs and antibiotic therapy. A purple serpiginous lesion was observed in the abdomen, and then the possibility of disseminated strongyloidiasis was raised, which was later confirmed by positive gastric wash and tracheal aspirate cultures. Subcutaneous ivermectin was started, due to the impossibility of intestinal absorption and due to hemodynamic instability and high gastric residue. Four days after the start of ivermectin and culture-guided antibiotic therapy, the patient died. Disseminated strongyloidiasis continues to be considered a global health challenge, particularly in the transplanted population, in which the infection is correlated with a high mortality. The diagnosis is often delayed and should be considered in the differential diagnosis of patients with multiple-organ failure.
\end{abstract}

Keywords: Solid organ transplantation; Disseminated strongyloidiasis; Strongyloides stercoralis; Immunocompromise.

\section{Resumen}

Strongyloides stercoralis es un helminto con distribución mundial y tiene la capacidad de promover la infección intestinal, que puede progresar a estrongiloidiasis diseminada. Las manifestaciones clínicas de la estrongiloidiasis diseminada varían ampliamente y los pacientes inmunodeprimidos tienen riesgo de infección sintomática. Un hombre de 38 años fue sometido a un doble trasplante de riñón-páncreas en diciembre de 2019 por diabetes mellitus tipo 1 e insuficiencia renal crónica por diálisis. Ingresó en la enfermería de trasplantes de riñón con náuseas, vómitos y dolor abdominal, que había comenzado 5 días antes. Ante la posibilidad diagnóstica de gastroenteritis infecciosa, se inició antibioterapia. El paciente evolucionó con empeoramiento de la ventilación asociado a descenso del sensorio, siendo derivado a la Unidad de Cuidados Intensivos, donde fue intubado y puesto en soporte ventilatorio. Como el paciente se encontraba en estado crítico y hemodinámicamente inestable, requirió fármacos vasoactivos y antibioterapia. Se observó una lesión serpiginosa púrpura en el abdomen, y luego se planteó la posibilidad de estrongiloidiasis diseminada, que luego se confirmó mediante lavado gástrico positivo y cultivos de aspirado traqueal. Se inició ivermectina subcutánea, por imposibilidad de absorción intestinal y por inestabilidad hemodinámica y elevado residuo gástrico. Cuatro días después del inicio de la antibioticoterapia guiada por ivermectina y cultivo, el paciente falleció. La estrongiloidiasis diseminada continúa siendo considerada un desafío de salud global, particularmente en la población trasplantada, en la que la infección se correlaciona con una alta mortalidad. El diagnóstico a menudo se retrasa y debe tenerse en cuenta en el diagnóstico diferencial de pacientes con insuficiencia multiorgánica.

Palabras clave: Trasplante de órganos sólidos; Estrongiloidiasis diseminada; Strongyloides Stercoralis; Inmunodepresión. 


\section{Introdução}

O Strongyloides stercoralis (S. stercoralis) é um helminto com distribuição mundial e tem a capacidade de promover infecção intestinal e causar um quadro clínico denominado estrongiloidíase disseminada (Heydarian et al., 2019). Este nematódeo é endêmico em regiões tropicais e subtropicais, como África, Ásia, América Central e América do Sul (Mobley et al., 2017).

Estimar a real prevalência global da infecção por S. stercoralis é um desafio, principalmente devido ao seu subdiagnóstico. No entanto, a literatura recente sugere que este nematódeo afeta entre 10 e $40 \%$ da população em países tropicais e subtropicais (Vasquez-Rios et al., 2019). Vale ressaltar que os níveis de saneamento e higiene pessoal são inversamente proporcionais ao índice de infecção (Ferreira et al., 2012).

Em uma situação de comprometimento do estado imunológico do hospedeiro, o ciclo de vida do parasita se perpetua, permitindo a proliferação de larvas para diversos órgãos do corpo humano (Vasquez-Rios et al., 2019). As complicações clínicas da estrongiloidíase disseminada são decorrentes do aumento do número de larvas, que também podem promover translocação bacteriana, agravando ainda mais o quadro clínico dos pacientes (Mukaigawara et al., 2020).

As manifestações clínicas da estrongiloidíase disseminada variam amplamente. Rotineiramente, os indivíduos saudáveis geralmente são assintomáticos, mesmo que cronicamente infectados. No entanto, os pacientes imunocomprometidos estão em risco de infecção disseminada sintomática (Izquierdo et al., 2013). Assim, vários sistemas orgânicos podem ser afetados, o que pode causar sepse (Pukkila-Worley et al., 2014), pneumonia (Kishaba et al., 1982) e meningite (Mukaigawara et al., 2018).

O reconhecimento precoce da disseminação é fundamental e deve ser suspeitado com base na análise de uma história clínica e epidemiológica efetiva, associada aos resultados de exames laboratoriais ${ }^{\mathbf{1 0}}$.

Por ser uma doença tropical negligenciada, a estrongiloidíase costuma ser esquecida, especialmente em locais onde essa condição é endêmica. A síndrome da hiperinfecção por Strongyloides stercoralis é, na verdade, uma doença emergente com apresentação clínica variável e com potencial de gravidade (Robson et al., 2009). Portanto, o conhecimento dessa condição e a conscientização dos profissionais de saúde sobre essa possibilidade diagnóstica é de extrema importância (Pacheco-Tenza et al., 2018).

Neste estudo, o objetivo é descrever um caso atípico e fatal de estrongiloidíase disseminada em um paciente com história de transplante duplo de pâncreas-rim, que estava sob cuidados médicos da equipe de terapia intensiva em um centro de referência no Nordeste do Brasil. Tal caso impactou na mudança do protocolo de prevenção de estrongiloidiase disseminada do centro de transplante de orgãos do Hospital Geral de Fortaleza.

\section{Metodologia}

O presente estudo trata-se de um estudo de caso, realizado a partir da coleta de dados em prontuário médico e revisão de literatura sobre estrongiloidiase disseminada em base de dados como Pubmed, Scielo e Lilacs, usando os descritores: "estrongiloidiase disseminada"; "Strongyloides stercoralis"; "imunocomprometido"; "transplante de órgãos sólidos". Após extensa pesquisa online, identificamos 18 estudos, os quais envolvem episódios de casos de strongiloidíase disseminada em pacientes imunocomprometidos. A Quadro 1 resume os principais artigos encontrados e seus resultados relatados. Os princípios éticos foram respeitados e a obtenção das informações foi autorizada pela instituição de saúde envolvida, a partir da submissão à apreciação e à aprovação pelo comitê de ética em pesquisa do Hospital Geral de Fortaleza. Número do parecer: 2.435.893 
Research, Society and Development, v. 10, n. 15, e473101522845, 2021

(CC BY 4.0) | ISSN 2525-3409 | DOI: http://dx.doi.org/10.33448/rsd-v10i15.22845

Quadro 1 - Literature review of disseminated strongyloidiasis cases in the last 10 years*.

\begin{tabular}{|c|c|c|c|c|c|c|c|c|c|c|c|c|c|}
\hline Authors & $\mathrm{N}$ & $\begin{array}{l}\text { Age } \\
\text { (yrs } \\
\text { old) }\end{array}$ & Country & Comorbidities & Risk factor & $\begin{array}{c}\text { Transplant } \\
\text { time }\end{array}$ & $\begin{array}{c}\text { Corticosteroid } \\
\text { use }\end{array}$ & $\begin{array}{l}\text { Initial clinical } \\
\text { manifestations }\end{array}$ & $\begin{array}{c}\text { Diagnostic } \\
\text { method }\end{array}$ & $\begin{array}{c}\text { Strongyloidiasis } \\
\text { treatment }\end{array}$ & $\begin{array}{c}\text { Associated } \\
\text { complications }\end{array}$ & $\begin{array}{l}\text { Sepsis (result of } \\
\text { culture) }\end{array}$ & Death \\
\hline$\frac{\text { Izquierdo } e t}{\underline{a l}^{6}}$ & 1 & 32 & Bolivia & $\begin{array}{l}\text { Myeloid } \\
\text { Leukemia }\end{array}$ & $\begin{array}{l}\text { Allogeneic stem } \\
\text { cell } \\
\text { transplantation }\end{array}$ & 62 days & Yes & $\begin{array}{c}\text { Jaundice, } \\
\text { abdominal } \\
\text { pain, } \\
\text { hematochezia }\end{array}$ & $\begin{array}{c}\text { Stool } \\
\text { parasitological }\end{array}$ & $\begin{array}{c}\text { Rectal } \\
\text { ivermectin and } \\
\text { enteral } \\
\text { albendazole }\end{array}$ & $\begin{array}{l}\text { AKI, acute } \\
\text { hepatitis, } \\
\text { respiratory } \\
\text { failure }\end{array}$ & Yes $($ E. coli) & Yes \\
\hline$\frac{\text { Yazdanpanah }}{\text { et al. }^{14}}$ & 1 & 67 & Jamaica & $\begin{array}{l}\text { Diabetes } \\
\text { Mellitus }\end{array}$ & Diabetes Mellitus & B & No & $\begin{array}{l}\text { Weight loss, } \\
\text { vomiting, } \\
\text { intestinal } \\
\text { obstruction }\end{array}$ & $\begin{array}{c}\text { Duodenal } \\
\text { biopsy }\end{array}$ & Oral ivermectin & $\begin{array}{c}\text { Intestinal } \\
\text { obstruction }\end{array}$ & No & No \\
\hline$\frac{\text { Minamide }}{a^{15}}{ }^{15} t$ & 1 & 57 & Japan & B & $\begin{array}{c}\text { Mantle cell } \\
\text { gastroduodenal } \\
\text { lymphoma }\end{array}$ & B & No & $\begin{array}{l}\text { Abdominal } \\
\text { pain, fever }\end{array}$ & $\begin{array}{c}\text { Analysis of } \\
\text { gastric aspirate }\end{array}$ & Ivermectin & $\begin{array}{l}\text { Pneumonia } \\
\text { Meningitis }\end{array}$ & Yes & Yes \\
\hline$\frac{\text { Najafi }}{16}$ et al. & 1 & 78 & Iran & $\begin{array}{c}\text { Diabetes } \\
\text { Mellitus and } \\
\text { Nephrotic } \\
\text { syndrome }\end{array}$ & $\begin{array}{l}\text { Nephrotic } \\
\text { syndrome }\end{array}$ & B & Yes & $\begin{array}{l}\text { Purpuric } \\
\text { abdominal } \\
\text { injury, } \\
\text { dysuria, } \\
\text { vomiting, } \\
\text { cough }\end{array}$ & $\begin{array}{c}\text { Duodenal } \\
\text { biopsy }\end{array}$ & $\begin{array}{c}\text { Oral } \\
\text { albendazole }\end{array}$ & No & No & No \\
\hline$\frac{\text { Citrin et al. }}{17}$ & 1 & 24 & B & $\begin{array}{l}\text { Crack and } \\
\text { cocaine user }\end{array}$ & HIV & B & No & $\begin{array}{c}\text { Abdominal } \\
\text { pain, } \\
\text { vomiting, } \\
\text { diarrhea, } \\
\text { cough, }\end{array}$ & $\begin{array}{c}\text { Stool } \\
\text { parasitological }\end{array}$ & $\begin{array}{c}\text { Oral } \\
\text { albendazole and } \\
\text { ivermectin }\end{array}$ & $\begin{array}{l}\text { Respiratory } \\
\text { failure }\end{array}$ & Yes & Yes \\
\hline
\end{tabular}


Research, Society and Development, v. 10, n. 15, e473101522845, 2021

(CC BY 4.0) | ISSN 2525-3409 | DOI: http://dx.doi.org/10.33448/rsd-v10i15.22845

\begin{tabular}{|c|c|c|c|c|c|c|c|c|c|c|c|c|c|}
\hline & & & & & & & & $\begin{array}{l}\text { hemoptysis, } \\
\text { purpura. }\end{array}$ & & & & & \\
\hline $\begin{array}{l}\text { Cipriano et } \\
\quad a l .{ }^{18}\end{array}$ & 1 & 68 & Portugal & B & $\begin{array}{l}\text { Kidney } \\
\text { transplantation }\end{array}$ & 1 year & Yes & $\begin{array}{l}\text { Vomiting, } \\
\text { diarrhea, } \\
\text { dyspnea }\end{array}$ & $\begin{array}{c}\text { Bronchoalveolar } \\
\text { lavage }\end{array}$ & $\begin{array}{l}\text { Subcutaneous } \\
\text { ivermectin }\end{array}$ & $\begin{array}{l}\text { Respiratory } \\
\text { failure }\end{array}$ & No & Yes \\
\hline $\begin{array}{c}\text { Belga et al. } \\
19\end{array}$ & 1 & 60 & Ecuador & Meningioma & $\begin{array}{c}\text { Meningioma } \\
\text { complicated with } \\
\text { cerebral edema }\end{array}$ & B & Yes & $\begin{array}{l}\text { Purpuric } \\
\text { abdominal } \\
\text { injury }\end{array}$ & $\begin{array}{c}\text { Bronchoalveolar } \\
\text { lavage }\end{array}$ & $\begin{array}{l}\text { Oral ivermectin } \\
\text { and albendazole }\end{array}$ & No & Yes $(E$. coli $)$ & No \\
\hline $\begin{array}{l}\text { Ferreira et al. } \\
\qquad 4\end{array}$ & 1 & 50 & Brazil & B & $\begin{array}{l}\text { Kidney } \\
\text { transplantation }\end{array}$ & 4 months & Yes & $\begin{array}{l}\text { Asthenia, } \\
\text { weight loss, } \\
\text { fever, } \\
\text { dyspnea, } \\
\text { cough, } \\
\text { hemoptysis }\end{array}$ & $\begin{array}{c}\text { Bronchoalveolar } \\
\text { lavage }\end{array}$ & $\begin{array}{l}\text { Ivermectin and } \\
\text { thiabendazole }\end{array}$ & $\begin{array}{c}\text { Febrile } \\
\text { neutropenia, } \\
\text { AKI, } \\
\text { meningitis, } \\
\text { Respiratory } \\
\text { failure }\end{array}$ & Yes & Yes \\
\hline$\frac{\text { Konecny }}{a l .}{ }^{20}$ & 1 & 27 & Australia & B & $\begin{array}{c}\text { Crohn Disease } \\
\text { HIV } \\
\text { Hepatitis C }\end{array}$ & B & Yes & $\begin{array}{l}\text { Purpuric skin } \\
\text { lesion, } \\
\text { diarrhea and } \\
\text { weight loss }\end{array}$ & $\begin{array}{l}\text { Bronchoalveolar } \\
\text { lavage and skin } \\
\text { biopsy }\end{array}$ & $\begin{array}{c}\text { Subcutaneous } \\
\text { ivermectin, } \\
\text { Albendazole } \\
\text { and ivermectin } \\
\text { by nasogastric } \\
\text { tube }\end{array}$ & $\begin{array}{c}\text { AKI, } \\
\text { Cholestatic } \\
\text { hepatitis, } \\
\text { Fungal lung } \\
\text { abscess, } \\
\text { Myocarditis, } \\
\text { Fungal } \\
\text { cerebritis }\end{array}$ & $\begin{array}{l}\text { Yes (Clostridium } \\
\text { difficile e CMV) }\end{array}$ & Yes \\
\hline $\begin{array}{c}\text { Boodman et } \\
\text { al. }{ }^{21}\end{array}$ & 1 & 62 & Canada & $\begin{array}{c}\text { Diabetes } \\
\text { Mellitus, } \\
\text { Systemic } \\
\text { Arterial } \\
\text { Hipertensionand } \\
\text { Dyslipidemia }\end{array}$ & $\begin{array}{c}\text { Granulomatous } \\
\text { interstitial } \\
\text { nephritis }\end{array}$ & B & Yes & $\begin{array}{l}\text { Abdominal } \\
\text { pain }\end{array}$ & $\begin{array}{c}\text { Secretion of } \\
\text { tracheal aspirate }\end{array}$ & $\begin{array}{c}\text { Subcutaneous } \\
\text { ivermectin and } \\
\text { by nasogastric } \\
\text { tube, } \\
\text { Albendazole by } \\
\text { nasogastric tube }\end{array}$ & $\begin{array}{c}\text { AKI, } \\
\text { Respiratory } \\
\text { failure }\end{array}$ & $\begin{array}{c}\text { Yes (Enterococcus } \\
\text { faecium) }\end{array}$ & Yes \\
\hline
\end{tabular}


Research, Society and Development, v. 10, n. 15, e473101522845, 2021

(CC BY 4.0) | ISSN 2525-3409 | DOI: http://dx.doi.org/10.33448/rsd-v10i15.22845

\begin{tabular}{|c|c|c|c|c|c|c|c|c|c|c|c|c|c|}
\hline$\frac{\text { Heydarian }}{a l .{ }^{1}}$ et & 1 & 73 & Iran & B & $\begin{array}{l}\text { Ovarian } \\
\text { neoplasm }\end{array}$ & B & Yes & $\begin{array}{c}\text { Nausea, } \\
\text { anorexia, } \\
\text { fever, } \\
\text { cutaneous } \\
\text { purple }\end{array}$ & $\begin{array}{c}\text { Duodenal } \\
\text { biopsy }\end{array}$ & $\mathrm{D}$ & $\begin{array}{c}\text { Respiratory } \\
\text { failure }\end{array}$ & Yes & Yes \\
\hline $\begin{array}{l}\text { Lucas et al. } \\
\qquad 13\end{array}$ & 1 & 70 & $\begin{array}{c}\text { United } \\
\text { States of } \\
\text { America }\end{array}$ & $\mathrm{B}$ & Kidney transplant & $\begin{array}{l}6 \text { years } \\
\text { (C) }\end{array}$ & Yes & $\begin{array}{c}\text { Dyspnea, } \\
\text { hemoptysis } \\
\text { and cough, } \\
\text { abdominal } \\
\text { pain and } \\
\text { weight loss }\end{array}$ & $\begin{array}{l}\text { Colon biopsy, } \\
\text { Sputum } \\
\text { analysis, } \\
\text { Serology }\end{array}$ & Oral ivermectin & B & $\begin{array}{c}\text { Yes (Klebsiella } \\
\text { pneumoniae) }\end{array}$ & No \\
\hline$\frac{\text { Mohamed }}{a l .{ }^{22}}$ et & 2 & $\begin{array}{l}35 \\
(1) \\
43 \\
(2)\end{array}$ & Bangladesh & B & $\begin{array}{c}\text { Paroxysmal } \\
\text { nocturnal } \\
\text { hemoglobinuria } \\
\text { (1) } \\
\text { HIV and } \\
\text { lymphoma (2) }\end{array}$ & B & No $(1,2)$ & $\begin{array}{c}\text { Fever, } \\
\text { Abdominal } \\
\text { pain, Dyspnea } \\
(1) \\
\text { Abdominal } \\
\text { pain, } \\
\text { hematochezia } \\
\text { and weight } \\
\text { loss (2) }\end{array}$ & $\begin{array}{c}\text { Gastric and } \\
\text { duodenal biopsy } \\
(1,2)\end{array}$ & $\begin{array}{c}\text { Albendazole } \\
(1,2)\end{array}$ & $\begin{array}{c}\text { Pancytopenia } \\
\text { (1) } \\
\text { Respiratory } \\
\text { failure (1) }\end{array}$ & $\begin{array}{c}\text { Yes } \\
\text { (Stenotrophomonas) } \\
(1) \\
\text { No (2) }\end{array}$ & $\begin{array}{l}\text { Yes } \\
(1) \\
\text { No } \\
(2)\end{array}$ \\
\hline$\frac{\text { Shrestha }}{a l .}{ }^{23}$ & 2 & $\begin{array}{l}46 \\
(1) \\
36 \\
(2)\end{array}$ & $\begin{array}{l}\text { Asia (1) } \\
\text { Spain (2) }\end{array}$ & B & $\begin{array}{c}\text { Dermatomyositis } \\
\text { (1) } \\
\text { IgA Nephropathy } \\
(1) \\
\text { Acute } \\
\text { lymphoblastic } \\
\text { leukemia (2) }\end{array}$ & B & Yes $(1,2)$ & $\begin{array}{c}\text { Hemoptysis, } \\
\text { cough, } \\
\text { cutaneous } \\
\text { purpura (1) } \\
\text { Cough, fever, } \\
\text { nauseas (2) }\end{array}$ & $\begin{array}{c}\text { Bronchoalveolar } \\
\text { lavage }(1,2)\end{array}$ & $\begin{array}{l}\text { Ivermectin and } \\
\text { albendazole by } \\
\text { nasogastric tube } \\
\text { (1) }\end{array}$ & $\begin{array}{c}\text { Respiratory } \\
\text { failure }\end{array}$ & $\begin{array}{c}\text { Yes (E. coli, } \\
\text { Nocardia sp, } \\
\text { Klebsiella } \\
\text { pneumoniae) [1] } \\
\text { (Pseudomonas } \\
\text { aeruginosa) }[2]\end{array}$ & No \\
\hline
\end{tabular}


Research, Society and Development, v. 10, n. 15, e473101522845, 2021

(CC BY 4.0) | ISSN 2525-3409 | DOI: http://dx.doi.org/10.33448/rsd-v10i15.22845

\begin{tabular}{|c|c|c|c|c|c|c|c|c|c|c|c|c|c|}
\hline Tam et al. ${ }^{24}$ & 2 & $\begin{array}{l}67 \\
(1) \\
55 \\
(2)\end{array}$ & $\begin{array}{c}\text { Trinidad } \\
\text { (1) } \\
\text { Jamaica (2) }\end{array}$ & HTLV-1 $(1,2)$ & $\begin{array}{c}\text { Rheumatoid } \\
\text { arthritis and } \\
\text { Systemic lupus } \\
\text { erythematosus (1) } \\
\text { Crohn disease (2) }\end{array}$ & B & $\begin{array}{l}\text { No (1) } \\
\text { Yes (2) }\end{array}$ & $\begin{array}{c}\text { Headache, } \\
\text { seizures, } \\
\text { anorexia, } \\
\text { vomiting, } \\
\text { abdominal } \\
\text { pain, diarrhea } \\
\text { e weight loss } \\
\text { (1) } \\
\text { Weight loss } \\
\text { and fever (2) }\end{array}$ & $\begin{array}{c}\text { Cerebrospinal } \\
\text { fluid analysis } \\
\text { and serology (1) } \\
\text { Stool } \\
\text { parasitological } \\
\text { and } \\
\text { Bronchoalveolar } \\
\text { lavage (2) }\end{array}$ & $\begin{array}{c}\text { Subcutaneous } \\
\text { ivermectin and } \\
\text { albendazole (1) } \\
\text { Parenteral } \\
\text { ivermectin and } \\
\text { albendazole (2) }\end{array}$ & $\begin{array}{l}\text { Meningitis } \\
\qquad(1,2) \\
\text { Respiratory } \\
\text { failure }(1,2)\end{array}$ & $\begin{array}{c}\text { Yes }(\text { E. coli) }[1] \\
\text { Yes (Streptococcus } \\
\text { oralis and } \\
\text { Staphylococcus } \\
\text { coagulase-negative) } \\
{[2]}\end{array}$ & Yes \\
\hline $\begin{array}{l}\text { Wang et al. } \\
\qquad 25\end{array}$ & 1 & 63 & China & $\begin{array}{l}\text { Diabetes } \\
\text { Mellitus }\end{array}$ & $\begin{array}{l}\text { Asthma and } \\
\text { pulmonary } \\
\text { emphysema }\end{array}$ & B & No & $\begin{array}{c}\text { Fever and } \\
\text { cough }\end{array}$ & $\begin{array}{l}\text { Sputum analysis } \\
\text { and PCR testing }\end{array}$ & B & $\begin{array}{l}\text { Respiratory } \\
\text { failure }\end{array}$ & B & B \\
\hline$\frac{\text { Chowdhury }}{\text { et al. }^{26}}$ & 1 & 63 & Spain & Smoker & $\begin{array}{l}\text { Immune } \\
\text { thrombocytopenia }\end{array}$ & B & Yes & $\begin{array}{c}\text { Fatigue, } \\
\text { vomiting, } \\
\text { cutaneous } \\
\text { purpura and } \\
\text { weight loss }\end{array}$ & $\begin{array}{c}\text { Duodenal } \\
\text { biopsy }\end{array}$ & Oral ivermectin & $\begin{array}{c}\text { Syndrome of } \\
\text { inappropriate } \\
\text { antidiuretic } \\
\text { hormone } \\
\text { secretion }\end{array}$ & No & No \\
\hline $\begin{array}{l}\text { Boggild et } \\
\quad \text { al. }{ }^{27}\end{array}$ & 1 & 56 & Brazil & & Agranulocytosis & B & Yes & Asthenia & $\begin{array}{c}\text { Bronchoalveolar } \\
\text { lavage and } \\
\text { Duodenal } \\
\text { biopsy }\end{array}$ & $\begin{array}{c}\text { Subcutaneous } \\
\text { ivermectin and } \\
\text { albendazole }\end{array}$ & $\begin{array}{l}\text { Respiratory } \\
\text { failure }\end{array}$ & Yes & No \\
\hline
\end{tabular}

A Years old; B Uninformed; C Patient had antibody-mediated rejection and treated with azathioprine, tacrolimus, increased corticosteroids and intravenous immunoglobulin; D patient died before diagnosis was established; N Number of cases.

* Descriptors used: Disseminated Strongyloidiasis and transplantation; Disseminated Strongyloidiasis and transplantation

Fonte: Autores. 


\section{Apresentação do Caso}

AGS, 38 anos, natural de São Paulo, solteiro, católico, educador físico, foi submetido a transplante duplo de pâncreasrim em dezembro de 2019 devido a diabetes mellitus tipo 1 e insuficiência renal crônica dialítica.

Os órgãos foram provenientes de um doador falecido do sexo masculino, 50 anos, com traumatismo cranioencefálico como causa do óbito e não apresentava sinais de infecções até o momento da captação. A imunoglobulina anti-timócitos foi utilizada na dose de $6 \mathrm{mg} / \mathrm{kg}$ para indução de imunossupressão. O pós operatório se deu sem maiores intercorrências, tendo o paciente recebido alta 10 dias após o procedimento.

A imunossupressão de manutenção foi composta de tacrolimus e sirolimus, sem corticoide associado. Paciente apresentava os seguintes níveis séricos no momento da alta: janeiro de 2020: tacrolimus $10 \mathrm{ng} / \mathrm{mL}$ e sirolimus 5,99 ng / ml.

Em fevereiro de 2020, foi internado na enfermaria de transplante renal do Hospital Geral de Fortaleza com náuseas, vômitos e dores abdominais iniciadas 5 dias antes, sem febre até aquele momento. Logo antes da admissão, os níveis de imunossupressores estavam: tacrolimos $11 \mathrm{ng} / \mathrm{mL}$ e sirolimos 7,11 ng / ml.

Com a possibilidade diagnóstica de gastroenterite infecciosa, foi iniciada terapia empírica com ciprofloxacina e realizados testes bioquímicos gerais, função renal e hepática, amilase, lipase, culturas de sangue e urina, sumário de urina e radiografias de tórax e abdômen, todos inicialmente normais, exceto pela presença de anemia evidenciada no hemograma. (Tabela 1)

Tabela 1 - Exames laboratoriais.

\begin{tabular}{llll}
\hline Exames laboratoriais & Pré-transplante & Alta hospitalar & $\begin{array}{l}\text { Admissão na } \\
\text { enfermaria }\end{array}$ \\
\hline $\begin{array}{l}\text { Hemoglobina/ } \\
\text { Hematócrito }\end{array}$ & $13,2 / 39,1$ & $8,1 / 23,4$ & 5,8 \\
Leucograma & 7.400 & 6.700 & 6.800 \\
Segmentados & $4.484(60,6 \%)$ & $5.473(81,7 \%)$ & $5.916(87 \%)$ \\
Eosinófilos & $125(1,7 \%)$ & $180(2,7 \%)$ & $0(0 \%)$ \\
Linfócitos & $2.111(29 \%)$ & $264(4 \%)$ & $612(9 \%)$ \\
Plaquetas & 237.000 & 182.000 & 357.000 \\
Sódio & 134 & 134 & 123 \\
Potássio & 4,1 & 5,1 & 4,4 \\
Cálcio & 8,4 & 8,8 & 8,6 \\
Glicose & 247 & 104 & 152 \\
Magnésio & 1,6 & 1,9 & 1,8 \\
Amilase & 106 & 120 & 62 \\
Lipase & 111 & 65 & 39 \\
Fosfatase Alcalina & 71 & - & 89 \\
Ureia & 124 & 61 & 34 \\
Creatinina & 7,4 & 1,7 & 1,2 \\
Alt/Ast & $47 / 18$ & $31 / 17$ & 317 \\
Gama-Glutamil Trsnferase & 44 & - & \\
\hline & & & \\
\hline
\end{tabular}

Fonte: Autores.

Após três dias da admissão hospitalar, o paciente evoluiu com desconforto respiratório e o esquema antimicrobiano foi escalonado para piperacilina-tazobactam, oseltamivir e sulfametoxazol-trimetoprim, porém o paciente evoluiu com piora ventilatória, associada a declínio do sensório, sendo encaminhado para Unidade de Terapia Intensiva (UTI) do setor de 
transplante, onde foi intubado e colocado em suporte ventilatório. Foi realizada nova radiografia de tórax, que evidenciou infiltrado reticulonodular difuso e a tomografia de tórax com padrão de vidro fosco difuso.

Devido à significativa piora clínica e hemodinâmica, ampliou-se novamente o espectro antimicrobiano, sendo adicionado cobertura antifúngica e iniciado o uso de drogas vasoativas. Devido a deterioração ventilatória e da função renal, manobras de recrutamento alveolar e suporte dialítico foram iniciados. Apesar das medidas adotadas, paciente evoluiu de forma desfavorável, sendo suspensa a terapia imunossupressora.

As hemoculturas coletadas no início do quadro evidenciaram crescimento de Klebisiella pneumoniae sensível a carbapenêmicos. Embora o paciente estivesse com esquema terapêutico adequadamente ajustado, evoluiu com parada cardiorrespiratória em assitolia, que foi revertida no segundo ciclo de ressuscitação cardiopulmonar.

Figura 1 - Erupção purpúrica serpiginosa peri-umbilical com disseminação centrífuga, limitada ao abdome.

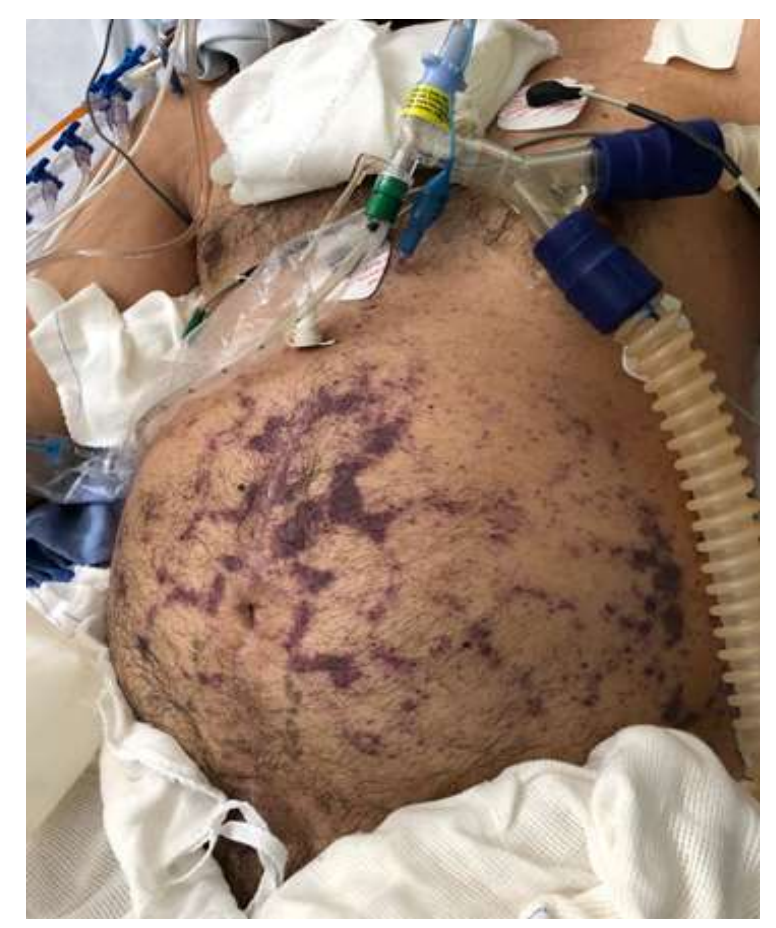

Fonte: Laboratório de patologia do HGF.

Neste dia, observou-se o aparecimento de lesões serpiginosas purpúricas restritas ao abdome (Figura A), que foi avaliada pelo serviço de dermatologia, sendo levantada a possibilidade de as lesões estarem relacionadas a estrongiloidíase disseminada. Pela impossibilidade de absorção intestinal, devido a instabilidade hemodinâmica e elevado resíduo gástrico, foi iniciada ivermectina subcutânea. A dose utilizada foi de $0,2 \mathrm{mg} / \mathrm{kg} /$ dia com ivermectina a $1 \%$, considerando o peso do paciente de 60 kg. Embora não haja recomendação para uso em humanos por esta via, esta conduta foi adotada como medida extrema, considerando a gravidade do paciente e com base na descrição da literatura ${ }^{10}$. Foi solicitada a triagem de Strongyloides stercoralis no aspirado gástrico e traqueal, bem como a PCR parasitológica e fecal FilmArray® para pesquisa da presença de Strongyloides nas fezes.

Quatro dias após o início da ivermectina e antibioticoterapia guiada por cultura, o paciente faleceu, com disfunção de múltiplos órgãos. Após seu óbito, foi confirmada a estrongiloidíase disseminada, com cultura de aspirado traqueal e gástrico positivas, nas quais foram identificadas larvas de Strongyloides stercoralis (Figuras B e C). A parasitologia de fezes e a biópsia de pele foram negativas. Além disso, os resultados do FilmArray® foram negativos. 
Figura 2 - Detecção de larvas de Strongyloides stercoralis em aspirado traqueal. Fig. 1.1 Coloração de Gram com ampliação de 400x; Fig. 1.2 coloração de Gram com ampliação de 1000x; Fig. 1.3 Coloração panatópica rápida com ampliação de 400x; Fig. 1.4 coloração recente com solução de Lugol com ampliação de 400x.

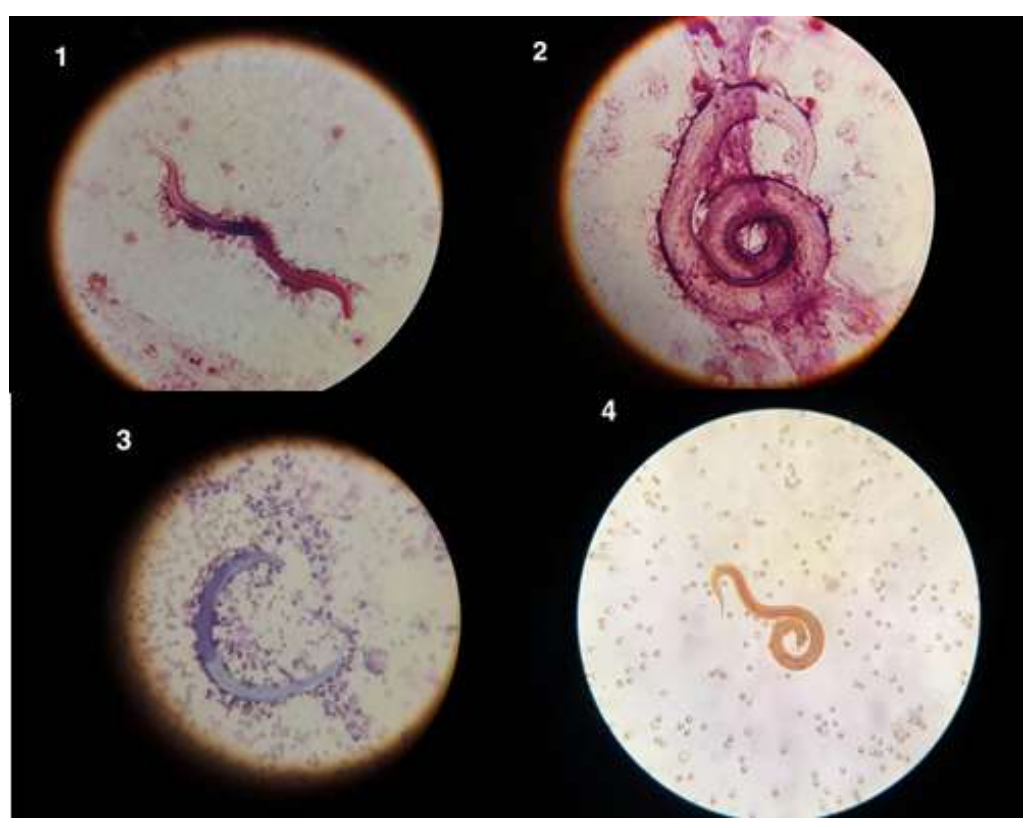

Fonte: Laboratório de patologia do HGF.

Figura 3 - Detecção de larvas de Strongyloides stercoralis no aspirado gástrico. Figura 5C coloração fresca com solução de iodo de Lugol com ampliação de 100x, em que se observa larvas de Estrongyloides stercoralis em aspirado gástrico.

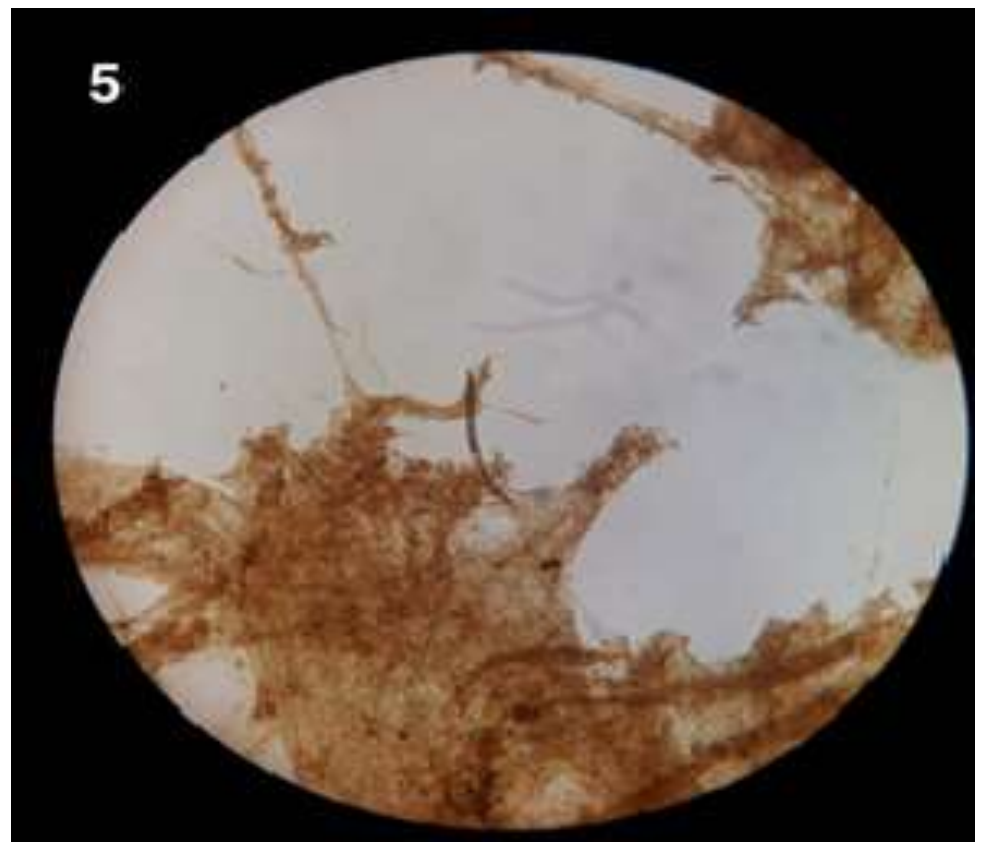

Fonte: Laboratório de patologia do HGF.

\section{Discussão}

As infecções são uma das principais causas de morbidade e mortalidade em receptores de transplantes de órgãos sólidos. Constituem um desafio para o diagnóstico e tratamento, uma vez que os indivíduos atingidos podem não manifestar os sinais e sintomas típicos dessa patologia e o tratamento é menos eficaz devido ao uso de drogas imunossupressoras (Lucar et al., 2018). O presente estudo relata um caso fatal de estrongiloidíase disseminada em um paciente transplantado de pâncreas-rim. A 
infestação por esse parasita é comumente subdiagnosticada, pois a maioria dos casos é assintomática ou oligossintomática. Porém em indivíduos imunocomprometidos, como no caso aqui relatado, pode afetar diversos sistemas do organismo (pulmão, baço, rim, pele e cérebro), com altas taxas de mortalidade (Mobley et al., 2017).

Houve atraso inicial no diagnóstico, pois o mesmo havia recebido profilaxia com albendazol no pós-operatório, sendo os sintomas inicialmente atribuídos a gastroenterite aguda. No entanto, a evolução foi adversa, apesar do tratamento intensivo. A presença da lesão cutânea foi fundamental para levantar a possibilidade diagnóstica de Estrongiloidíase Disseminada.

A síndrome de hiperinfecção por Strongyloides pode causar intensa translocação bacteriana e quadros sépticos associados principalmente a microrganismos Gram-negativos (Mobley et al., 2013). O nematódeo se espalha por via hematogênica para outros sistemas, como os pulmões, causando insuficiência respiratória aguda (Mobley et al., 2013; Boggild et al., 2016). Kim et al., (2016) identificaram 27 casos de S. stercoralis em receptores de órgãos sólidos, nos quais foi observada mortalidade de $35 \%$, sendo sepse e bacteremia fortes preditores de óbito. No caso aqui apresentado, foi identificada a presença de Klebsiella pneumonia em culturas de sangue e urina. Certos fatores de risco podem apoiar o desenvolvimento da doença em sua forma disseminada, incluindo pacientes idosos, corticoterapia prolongada, história de transplantes, síndrome da imunodeficiência adquirida e doenças malignas. Uma revisão sistemática de casos de estrongiloidíase grave relatou que 67\% dos indivíduos tinham história de uso recente de corticosteroide antes do início dos sintomas, enquanto história de infecção pelo vírus da imunodeficiência humana estava presente em 15\% dos casos e 11,5\% dos casos eram pacientes transplantados (Mobley et al., 2013). Vale ressaltar que o paciente apresentava fatores de risco importantes para o desenvolvimento da estrongiloidíase disseminada, como história epidemiológica de residir em país localizado em área tropical e por ser receptor de órgãos sólidos.

O curso da doença no presente caso é semelhante ao relatado na literatura, com predomínio de sintomas gastrointestinais inespecíficos, como dor abdominal, náuseas e vômitos. Esses sintomas clínicos podem aumentar a dificuldade de diagnóstico, pois várias condições podem ter manifestações iniciais semelhantes. É importante ressaltar que apesar do uso recente do albendazol, resistência a esse medicamento tem sido descrita na literatura, mesmo com a existência da recomendação em bula para o seu uso (Henriquez-Camacho et al., 2016). Assim, os profissionais de saúde devem ter alta suspeita de hiperinfecção por estrongilóides, dada a gravidade do quadro clínico. Além disso, o paciente descrito neste relato teve evolução adversa, necessitando de múltiplos esquemas de antibióticos devido ao quadro séptico associado. O comprometimento pulmonar foi observado por meio de exames de imagem, que mostraram padrão em vidro fosco na tomografia de tórax e por meio de insuficiência respiratória aguda com necessidade de suporte ventilatório (Vasquez-Rios et al., 2019).

A púrpura cutânea é uma manifestação rara de estrongiloidíase disseminada, secundária à migração larval através dos vasos intradérmicos e através das veias periféricas da circulação portal (Weiser et al., 2011; Osio et al., 2014). Normalmente, este sinal clínico mostra uma distribuição purpúrica peri-umbilical, bem como na região proximal dos membros inferiores (Najafi et al., 2016). A ventilação mecânica invasiva com pressão positiva pode contribuir para o aparecimento deste sinal, devido ao aumento da pressão no sistema porta e ao desvio portossistêmico pelas veias umbilical e periumbilical (Citrin et al., 2017). Em consonância com os casos descritos na literatura, este caso apresentava lesões periumbilicais purpúricas após o início do suporte ventilatório invasivo, motivo que levou a considerar a hiperinfecção por Strongyloides stercoralis como a principal hipótese diagnóstica.

A transmissão da estrongiloidíase em pacientes com história de transplante de órgãos sólidos pode ocorrer como um caso de (1) reinfecção, (2) transmissão por meio de doadores infectados com Strongyloides stercoralis ou (3) reativação de uma infecção latente em pacientes que não foram tratados adequadamente antes do transplante (Hamilton et al., 2011). A transmissão da infecção pelo doador é um evento raro, tendo sido descrito em dois estudos de revisão nas últimas duas décadas, nos quais apenas 27 pacientes tiveram a transmissão do doador como causa da doença (Kim et al., 2016). A reinfecção ou ativação de infecções latentes são consideradas as causas mais comuns na prática clínica (Le et al., 2014). Além disso, os pacientes são 
assintomáticos nos primeiros seis meses após o transplante e desenvolvem condições inespecíficas ou disseminadas após o início do regime imunossupressor (Kim et al., 2016).

Em pacientes transplantados, que inevitavelmente serão imunossuprimidos, a melhor forma de prevenção continua sendo a profilaxia antiparasitária para todos, uma vez que já é realizada rotineiramente (Marty et al., 2005). No entanto, não há consenso na literatura sobre a profilaxia ideal. Existem poucos estudos clínicos que buscaram avaliar o melhor esquema antihelmíntico, com alguns relatos na literatura mostrando baixa eficácia em relação ao uso do albendazol (Marti et al., 1996). Outros sugerem que o uso profilático de ivermectina seria mais eficaz devido à sua baixa toxicidade e capacidade de promover a melhora clínica mais eficaz nas formas disseminadas de estrongiloidíase (Portugal et al., 2002; Camargo et al., 2019). Portanto, o relato descrito, juntamente com os estudos analisados na literatura, serviu de base para a mudança do regime profilático dos pacientes submetidos ao transplante de órgãos sólidos em nosso serviço, indicando preferencialmente o uso de ivermectina profilática.

Os exames laboratoriais parecem ser de pouca utilidade nos casos de estrongiloidíase disseminada. Além disso, pacientes que vivem em áreas endêmicas podem apresentar resultados falso-positivos em testes laboratoriais. Métodos sorológicos para determinar a presença de anticorpos no soro do hospedeiro podem auxiliar no diagnóstico de pacientes assintomáticos com eosinofilia no hemograma. No entanto, o diagnóstico definitivo é baseado no achado de larvas em amostras de fezes, secreção traqueal, lavado broncoalveolar, aspirado gástrico ou amostras de biópsia (Olivia et al., 2007). Em um estudo publicado por Salluh et al., (2005) o aspirado traqueal foi positivo para a presença de Strongyloides stercoralis em 83\% dos casos, enquanto a triagem direta do aspirado gástrico, biópsia de pele e pulmão foi positiva em $66 \%$ dos casos.

No caso relatado, foi identificada a presença do nematódeo em culturas de traqueia e aspirado gástrico, estabelecendo o diagnóstico. Além disso, o helminto não foi encontrado nas amostras de biópsia de pele.

$\mathrm{O}$ tratamento da infecção disseminada ainda é um desafio devido à gravidade do paciente e também às controvérsias na literatura quanto ao melhor medicamento a ser utilizado. Assim, recomenda-se o início precoce dos anti-helmínticos e a redução das terapias imunossupressoras. É extremamente importante fornecer o tratamento adequado para condições sépticas com antibióticos de amplo espectro e terapia intensiva (Izquierdo et al., 2013; Balkhair et al., 2019). No caso aqui descrito, devido à gravidade clínica, o paciente foi internado em terapia intensiva e recebeu tratamento anti-helmíntico e antibióticos. Vale ressaltar que o diagnóstico neste caso foi tardio, fato que impossibilitou a implantação da terapia em tempo hábil para promover melhora clínica adequada. Assim, os profissionais de saúde devem ter alta suspeição para possíveis casos de estrongiloidíase disseminada, principalmente em pacientes imunossuprimidos, que apresentam maior probabilidade de evolução adversa.

Estudos mais consistentes têm demonstrado que a ivermectina é o melhor tratamento para a doença, pois proporciona melhores resultados em termos de eficácia e tolerabilidade (Mohamed et al., 2017). A forma subcutânea para uso veterinário não foi aprovada para uso em humanos, mas foi descrita como opção terapêutica em estudos com pacientes críticos (Marty et al., 2005; Barrett et al., 2016).

Vale ressaltar que o albendazol ainda é utilizado em alguns centros, embora tenha baixa eficácia e mais efeitos colaterais, como reações de hipersensibilidade, aumento das transaminases, sintomas gastrointestinais, cefaleia, entre outros. Isso pode ser devido à disponibilidade limitada de ivermectina em muitos países. Um estudo sistemático da Cochrane analisou sete ensaios clínicos randomizados em adultos com infecção por Strongyloides stercoralis, nos quais a eficácia do tratamento de pacientes com ivermectina ou albendazol isoladamente foi comparada. Os resultados mostraram que o tratamento com ivermectina foi mais eficaz, além de curar um maior percentual de pacientes e apresentar melhor tolerabilidade (Henriquez-Camacho et al., 2016).

Alguns especialistas afirmam ainda que a associação de ivermectina e albendazol pode resultar em uma melhor resposta terapêutica, mas não há estudos que comprovem este fato (Henriquez-Camacho et al., 2016). Em casos críticos, nos quais o paciente tem absorção intestinal errática ou é hemodinamicamente instável, a terapia com ivermectina subcutânea pode ser usada 
empiricamente (Marty et al., 2005; Barrett et al., 2016). No caso relatado, devido à não especificidade dos sinais e sintomas, o diagnóstico e a terapia com ivermectina subcutânea foram postergados, o que provavelmente impactou na evolução do paciente. Portanto, reforça-se a importância da suspeita precoce de hiperinfecção por Strongyloides nos grupos de maior risco.

\section{Conclusão}

Em resumo, a estrongiloidíase disseminada continua sendo considerada um desafio para a saúde global, principalmente na população transplantada, na qual a infecção está correlacionada a uma alta taxa de mortalidade. O diagnóstico costuma ser tardio devido à inespecificidade dos sintomas. Portanto, essa condição clínica deve ser considerada no diagnóstico diferencial de pacientes com falência de múltiplos órgãos refratários à antibioticoterapia convencional, principalmente quando o paciente apresenta perfil epidemiológico relevante. As taxas de sobrevivência estão diretamente relacionadas ao tempo de implementação do tratamento adequado e podem até tornar o manejo da estrongiloidíase um desafio. A ivermectina oral continua sendo a terapia de escolha, mas a forma subcutânea de uso veterinário, apesar de não ter sido aprovada para uso em humanos, tem sido descrita como opção terapêutica em pacientes críticos. Por consequência, o relato descrito, juntamente com os estudos analisados na literatura, serviu de base para a mudança do regime profilático dos pacientes submetidos ao transplante de órgãos sólidos em nosso serviço, indicando preferencialmente o uso de ivermectina profilática. Mais estudos, se fazem necessário para definir o real impacto de tal conduta.

\section{Interesses Competitivos}

Os autores declaram que não têm interesses conflitantes

\section{Fontes de Financiamento}

Esta pesquisa não recebeu nenhum subsídio específico de agências de fomento nos setores público, comercial ou sem fins lucrativos.

\section{Referências}

Balkhair, U. M. A., Taher, H. B., Busaidi, I., Amin, M. A., Al-Khirbash, U. M. A., Adawi, B. A., et al. (2019). Estrongiloidíase disseminada complicada por hemorragia alveolar, meningite e choque séptico tratada com albendazol e ivermectina subcutânea. Int J Infect Dis, 86: 44-46.

Barrett, J. \& Newsholme, W. (2016). Uso de ivermectina subcutânea no tratamento da infecção grave por Strongyloides Stercoralis: dois relatos de caso e uma discussão da resposta dos autores da literatura. J Antimicrob Chemother,71 (4): 1131.

Belga, S., MacDonald, C. \& Houston, S. (2019). Estrongiloidíase disseminada. JAMA Dermatol.

Boggild, A. K., Libman, M., Greenaway, C. \& McCarthy, A. E. (2016). Declaração CATMAT sobre estrongiloidíase disseminada: prevenção, avaliação e diretrizes de gestão. Can Commun Dis Rep, 42: 12-19.

Boodman, C. ; Chhonker, Y. S. ; Murry, D. J. ; Mah, U. M. A. ; Conceder, J.; Steiner, T.; et al (2018). Relato de Caso: Concentrações plasmáticas de ivermectina e albendazol em paciente com estrongiloidíase disseminada em oxigenação por membrana extracorpórea e terapia de reposição renal contínua. Am J Trop Med Hyg, 99 (5): 1194-1197

Buonfrate, D., Requena-Mendez, A., Angheben, A., Munoz, J., Gobbi, F., Ende, J. V. D., et al (2013). Estrongiloidíase grave: uma revisão sistemática de relatos de casos. BMC Infect Dis, 13: 78.

Camargo, J. F., Simkins, J., Anjan, S., Guerra, G., Vianna, R., \& Salama, S. (2019). Implementação de uma Estratégia de Rastreio de Strongyloides em Doadores e Receptores de Transplante de Órgãos Sólidos. Clin Transplant. 2019,33 (4): e13497.

Chowdhury, D. N., Dhadham, G. C., Xá, U. M. A. \& Baddoura, W. (2014). Syndrome of Inadequada Antidiuretic Hormone Secreion (SIADH) in Strongyloides stercoralis Hyperinfection. J Glob Infect Dis, $6(1): 23-27$.

Cipriano, U. M. A., Dias, R., Marinho, R., Correia, S., Lopes, V., Cardoso, T., et al (2020). Hiperinfecção fatal derivada de doador Estrongiloidíase em receptor de transplante renal. IDCases,16; 19: e00703.

Citrin, P., Guzmán, J. A., Barros, J. \& Machado-Filho, C. D. (2017). Lesão purpúrica em um paciente imunocomprometido: uma apresentação de estrongiloidíase disseminada. J Eur Acad Dermatol Venereol, 31 (8): e380-e381. 
Ferreira, C. J. A., Da silva, D. A., Almeida, P. H., Da Silva, L. S. V., Carvalho, V. P., Coutinho, A. F., et al (2012). Estrongiloidíase disseminada fatal após transplante renal. Rev. Soc. Bras. Med. Trop, 45: (5).

Hamilton, K., Abt, P. L., Rosenbach, M., Bleicher, M. B., Levine, M. S., et al (2011). Infecção por Strongyloides stercoralis derivada de doador em receptores de transplante renal. Transplantação, 91: 1019-1024.

Henriquez-Camacho, C., Gotuzzo, E., Echevarria, J., Júnior White, A. C., Terashima, A., Samalvides F., et al (2016). Ivermectina versus albendazol ou tiabendazol para infecção por Strongyloides stercoralis. Cochrane Database Syst Rev,1: 1-50.

Heydarian, P., Mobedi, E. U., Mohaghegh, M. A., Hosseini, U. M. A., Chegini, F. G. \& Esboei, B. R. (2019). Um caso de estrongiloidíase disseminada fatal acompanhada de obstrução intestinal. Relatórios de casos da Oxf Med, (10): omz087.

Izquierdo, E. U., Briones, J., Lluch, R., Arqueros, C. \& Martino, R. (2013). Fatal Strongyloides hiperinfecção complicando uma sepse gram-negativa após transplante alogênico de células-tronco: um relato de caso e revisão da literatura. Case Rep Hematol, $2013: 860976$.

Kim, J. H., Kim, D. S., Yoon, Y. K., Sohn, J. W. \& Kim, M. J. (2016). Infecção por estrongiloidíase doentiva em receptores de transplante de órgãos sólidos: uma revisão e análise agrupada. Transplant Proc, 48 (7): 2442-2449

Kishaba; T (1982). Estrongiloidíase e infecções devido a organismos entéricos: sepse, pneumonia e meningite causada por bactérias Gram-negativas associadas à estrongiloidíase disseminada [em japonês]. Infecção, 12: 180.

Konecny, P., Weatherall, C. J., Adhikari, S., Duflou, J., Marjoniemi, V., Pretório, C. J. et al (2018). Relato de Caso: Farmacocinética da Ivermectina Subcutânea na Infecção por Strongyloides Disseminada: Análise Plasmática e Pós-morte. Am J Trop Med Hyg, 99 (6): 1580-1582.

Le, M., Ravin, K., Hasan, A., Clauss, H., Muchant, D. G., Pasko, J. K., et al (2014). Estrongiloidíase derivada de um único doador em três receptores de transplante de órgãos sólidos: série de casos e revisão da literatura. Am J Transplant,14: 1199-1206.

Lucar, A., Knicely, D. H. \& Sifri, C. D. (2018). Síndrome de Hiperinfecção por Strongyloides Tardio Pós-Transplante Renal. Transpl Infect Dis, 20 (6): e12975.

Marti, H., Haji, H. J., Savioli, L., Chwaya, H. M., Mgeni, A. F., Ameir, J. S., et al (1996). Um ensaio comparativo de uma ivermectina em dose única versus três dias de albendazol para o tratamento de Strongyloides stercoralis e outras infecções por helmintos transmitidas pelo solo em crianças. Am J Trop Med Hyg, 55: $477-481$.

Marty, F. M., Lowry, C. M., Rodriguez, M., Milner, D. A., Pieciak, W. S., Sinha A., et al (2005). Tratamento da estrongiloidíase disseminada humana com uma formulação veterinária parenteral de ivermectina. Clin Infect Dis, 41: e5-e8.

Minamida, T., Fukushima, M. \& Inokuma, T. (2018). Envolvimento gastroduodenal na estrongiloidíase disseminada. JGH Open,2 (2): 75-76.

Mobley, C. M., Dhala, A. \& Ghobrial, R. M. (2017). Strongyloides stercoralis no transplante de órgãos sólidos: o diagnóstico precoce pega o verme. Curr Opin Organ Transplant, 22 (4): 336-344.

Mohamed, R., Hamodat, M. \& Al Abbadi, M. A. (2017). Estrongiloidíase Gástrica: Relato de 2 Casos e Breve Revisão da Literatura. Lab Med, 48 (1): 93-96.

Moura, E. B., Maia, M. O., Ghazi, M., Amorim, F. F. \& Pinhati, H. M. (2012). Tratamento de salvamento da estrongiloidíase disseminada em um paciente imunocomprometido: sucesso da terapia com ivermectina subcutânea. Braz J Infect Dis, 16 (5): 479-81.

Mukaigawara, M., Nakayama, I. \& Gibo K. (2018). Strongyloidiasis and culture-negative suppurative meningitis, Japan, 1993-2015. Emerg Infect Dis, 24: 2378-80.

Mukaigawara, M., Narita, M., Shiiki, S., Takayama, Y., Takakura, S. \& Kishaba, T. (2020). Clinical Characteristics of Disseminated Strongyloidiasis, Japan, 1975-2017.Emerg Infect Dis, 26 (3): 401-408.

Najafi, N., Soleymani, E., Sarvi, S., Marofi, U. M. A., Nosrati, U. M. A. \& Davoodi, A. (2016). Estrongiloidíase disseminada em um paciente iraniano imunocomprometido: um relato de caso. Iran J Parasitol, 11 (2): 279-283.

Olivia, B. L., Graselli, R., Ananias, M., Pinto, T.S., Bozza, F.A., Soares M., et al (2007). Estrongiloidíase disseminada: DIagnossis e tratamento. RBT, 19 (4): 463-68.

Osio, A., Demongekt, C., Battistella, M., Lhuillier, E., Zafrani, L. \&Vignon-Pennamen, M. D. (2014). Púrpura Periumbilical: Desafio. Am J Dermatopathol, 36: $899-900$.

Pacheco-Tenza, M. I., Ruiz-Macia, J. A., Navarro-Cots, M., Gregori-Colome, J., Cepeda-Rodrigo, J. M. \& Lenas- Garcia, J. (2018). Infecção por Strongyloides stercoralis em um hospital regional espanhol: Não apenas uma doença importada. Enferm Infecc, 36 (1): 24-28.

Portugal, R., Schaffel, R., Almeida, L., Spector, N. \& Nucci, M. (2002). Tiabendazol para a profilaxia da estrongiloidíase em pacientes imunossuprimidos com doenças hematológicas: um estudo randomizado duplo-cego controlado por placebo. Haematologica, 87: 663-664

Pukkila-Worley, R., Nardi, V. \& Branda, J. A. (2014). Registros de casos do Hospital Geral de Massachusetts. Caso 28-2014. Um homem de 39 anos com erupção na pele, dor de cabeça, febre, náuseas e fotofobia. N Engl J Med, 371: 1051-60.

Robson, D., Beeching, N. J. \& Gill G. V. (2009). Síndrome de hiperinfecção por Strongyloides em veteranos britânicos. Ann Trop Med Parasitol, 103 (2): 145 \pm 8 .

Salluh, J. I. F., Bozza, F. A., Pinto, T. S., Toscano, L., Weller, P. F. \& Soares, M. (2005). Púrpura periumbilical cutânea em estrongiloidíase disseminada em pacientes com câncer: uma característica patognomônica de doença potencialmente letal? Braz J Infect Dis, 9 (5): 419 -424. 
Research, Society and Development, v. 10, n. 15, e473101522845, 2021

(CC BY 4.0) | ISSN 2525-3409 | DOI: http://dx.doi.org/10.33448/rsd-v10i15.22845

Shrestha, P., O'Neil, S. E., Taylor, B. S., Bode Omoleye, O. \& Anstead, G. M. (2019). Hemoptise no paciente imunocomprometido: não se esqueça da estrongiloidíase. Trop Med Infect Dis, 4 (1): 35.

Tam, J., Schwartz, K. L., Keystone, J., Dimitrakoudis, D., Downing, M. \& Krajden, S. (2019). Relato de caso: Estrongiloidíase do sistema nervoso central: dois casos diagnosticados antes da morte. Am J Trop Med Hyg, 100 (1): 130-134.

Vasquez-Rios, G., Pineda-Reyes, R., Pineda-Reyes, J., Marin R., Ruiz, E. F. \& Terashima, A. (2019). Síndrome de hiperinfecção por Strongyloides stercoralis: uma compreensão mais profunda de uma doença negligenciada. J Parasit Dis, 43 (2): 167-175.

Wang, L. F., Xu, E. U., Luo, S. Q., Xie, H., Chen, C., Wu, Z. D., et al (2017). Diagnóstico de Strongyloides Stercoralis por Características Morfológicas Combinadas com Métodos Biológicos Moleculares. Parasitol Res, 116 (4): 1159-1163.

Weiser, J. A., Scully, B. E., Bulman, W. A., Husain, S. \& Grossman M. E. (2011). Púrpura da impressão digital parasitária periumbilical: síndrome de hiperinfecção por Strongyloides adquirida em um transplante renal em cadáver. Trans Infect Dis,13: 58-62

Yazdanpanah, F., Saba, H., Rahmani, R. \& Schreiber, Z. J. (2020). Hindy Hiperinfecção por P. Strongyloides que se apresenta como uma obstrução do escoamento gástrico. Cureus, 12 (1): e660 